\title{
Avaliação da redução de potássio em hortaliças submetidas a diferentes métodos de cocção para possível utilização na dietoterapia renal
}

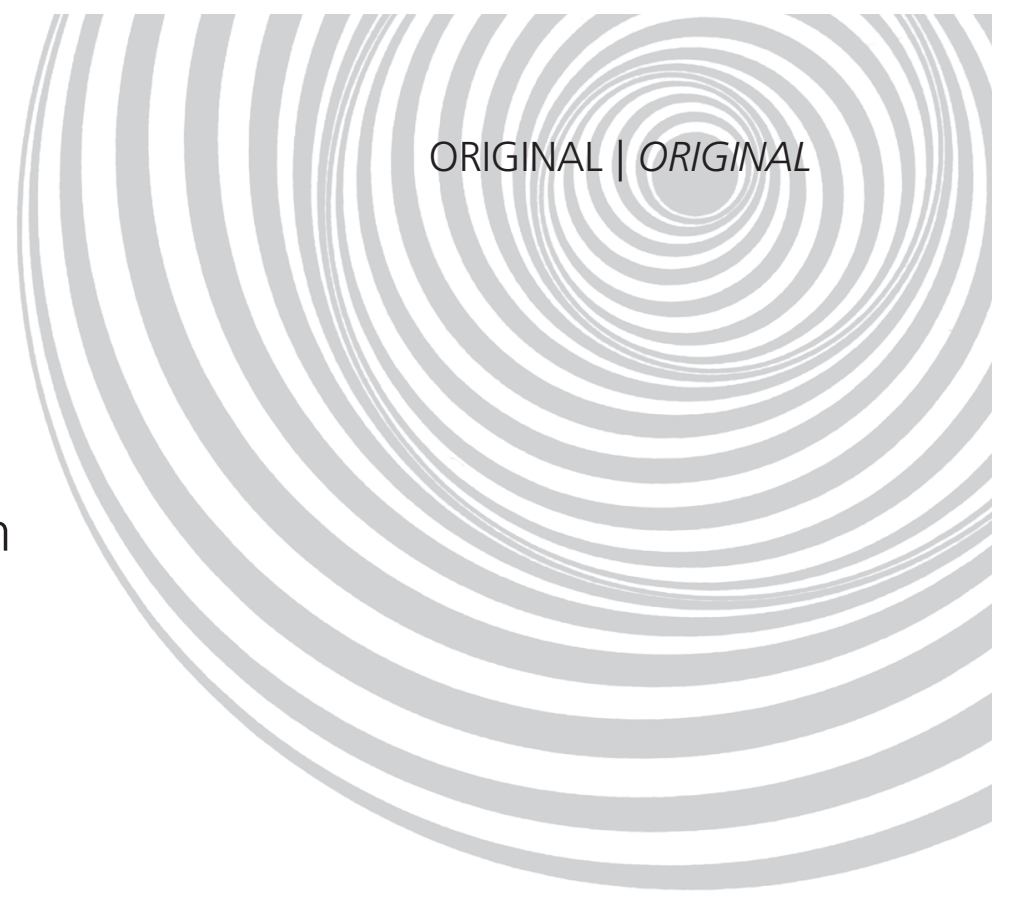

\author{
Evaluation of potassium in vegetables submitted \\ to different cooking methods and their \\ possible use in renal diet
}

Cristiane COPETTI ${ }^{1}$

Viviani Ruffo de OLIVEIRA2

Paula KIRINUS²

RE S U M O

\section{Objetivo}

Julgou-se relevante avaliar a concentração de potássio em vegetais crus submetidos ao remolho e cozidos sob diferentes formas - ebulição, micro-ondas e sob pressão - a fim de verificar se o remolho e as técnicas de cocção têm eficácia na redução da concentração desse mineral.

\section{Métodos}

O experimento foi realizado em delineamento casualizado, com esquema fatorial $3 \times 5$ (3 vegetais $\times 5$ procedimentos) e 3 repetições nas análises. As hortaliças - batata, cenoura e brócolis - foram submetidas à análise dos teores de potássio por fotometria de chama IL, e compararam-se os tratamentos: cru, remolho em água, cocção em ebulição, micro-ondas e sob pressão.

\section{Resultados}

Nas amostras analisadas, para a batata o método remolho (232,2mg/g), ebulição (197,3mg/g), micro-ondas $(170,3 \mathrm{mg} / \mathrm{g})$ e pressão $(187,2 \mathrm{mg} / \mathrm{g})$ não diferiram de forma estatisticamente significativa entre si, da mesma forma para a cenoura, que obteve os valores de redução de 315,0mg/g, 309,9mg/g, 243,3mg/g e 210,6mg/g, respectivamente para remolho, ebulição, micro-ondas e pressão. Entretanto, para os brócolis, pode-se observar que os métodos de preparo em micro-ondas $(280,1 \mathrm{mg} / \mathrm{g})$ e pressão $(167,3 \mathrm{mg} / \mathrm{g})$ diferiram estatisticamente em relação aos outros métodos, mostrando-se mais eficazes na redução dos teores de potássio dessa hortaliça.

\footnotetext{
1 Universidade Federal de Santa Catarina, Centro de Ciências Agrárias, Programa de Pós-Graduação em Ciência de Alimentos, Laboratório de Química de Alimentos. Rod. Admar Gonzaga, 1346, Itacorubi, 88034-001, Florianópolis, SC, Brasil. Correspondência para/Correspondence to: C. COPETTI. E-mail: <copetti.cris@gmail.com>.

2 Universidade Federal de Santa Maria, Centro Universitário Franciscano de Santa Maria, Curso de Nutrição. Santa Maria, RS, Brasil.
} 
832 | C. COPETTI et al.

\section{Conclusão}

O remolho e os métodos de cocção mostraram-se eficazes na redução dos teores de potássio nas hortaliças, no entanto fatores como tempo, temperatura, recipiente, potência e frequência das ondas eletromagnéticas do micro-ondas podem influenciar os diferentes tipos de cocção.

Termos de indexação: Dietoterapia. Hortaliças. Manipulação de alimentos. Potássio.

\section{A B S T R A C T}

\section{Objective}

This study assessed the concentration of potassium in raw and macerated raw vegetables and vegetables cooked by different methods - boiling, microwave and pressure-cooking - to verify if maceration and different cooking methods can effectively reduce the concentration of this mineral.

\section{Methods}

This experiment had a random $3 \times 5$ factorial design (3 vegetables $\times 5$ procedures) and the analyses were repeated 3 times. Flame photometry was used to determine potassium concentration in raw, soaked, boiled, microwaved and pressure-cooked potatoes, carrots and broccoli.

\section{Results}

Potassium concentration in soaked (232.2mg/g), boiled $(197.3 \mathrm{mg} / \mathrm{g})$, microwaved $(170 \mathrm{mg} / \mathrm{g})$ and pressurecooked (187.2mg/g) potatoes and soaked (315.0mg/g), boiled (309.9mg/g), microwaved (243.3mg/g) and pressure-cooked $(210.6 \mathrm{mg} / \mathrm{g})$ carrots did not differ significantly. On the other hand, potassium concentration in microwaved $(280.1 \mathrm{mg} / \mathrm{g})$ and pressure-cooked $(167.3 \mathrm{mg} / \mathrm{g})$ broccoli was significantly different from that found in soaked and boiled broccoli. Therefore, microwaving and pressure-cooking reduce the potassium concentration in broccoli more effectively.

\section{Conclusion}

Maceration and the different cooking methods were effective in reducing the concentration of potassium in the studied vegetables. However, other factors such as cooking length, temperature, type of container and microwave frequency and power level may also affect potassium concentration.

Indexing terms: Diet therary. Greens. Food handling. Potassium.

\section{N T R O D U ÇÃ O}

O potássio é um íon predominantemente intracelular e seu conteúdo corporal é de cerca de $3.500 \mathrm{mEq}$ para um adulto de aproximadamente $70 \mathrm{~kg}$. Sua concentração intracelular varia de 140 a $150 \mathrm{mEq} / \mathrm{l}$, sendo o tecido muscular o maior depósito de potássio. Apenas 2\% (3,5 a $5,0 \mathrm{mEq} / \mathrm{l})$ do potássio corporal total encontra-se no espaço extracelular. Devido à grande diferença entre as concentrações intra e extracelular de potássio, os fatores que controlam sua distribuição transcelular são determinantes para a manutenção de níveis séricos normais ${ }^{1}$.

Para que haja a manutenção do potássio corpóreo é necessário um balanço integrado, isto é, a ingestão e a absorção do potássio pelo intestino e a sua eliminação devem estar em equilíbrio.
Assim, em condições normais, um indivíduo deve ingerir cerca de $100 \mathrm{mEq}$ de potássio por dia, pois 90mEq serão eliminados na formação diária da urina e os outros $10 \mathrm{mEq}$ na formação das fezes².

Os rins constituem o principal sistema na regulação do volume líquido intravascular, na composição dos líquidos orgânicos e na excreção dos produtos finais do metabolismo celular. A circulação extracorpórea produz várias alterações na quantidade e na distribuição do fluxo sanguíneo renal, especialmente nos pacientes com alterações renais agudas ou crônicas ${ }^{3}$.

A insuficiência renal consiste na redução das funções renais e pode ocorrer em poucas horas ou dias ou, ao contrário, instalar-se insidiosamente, evoluindo lentamente ao longo de vários anos até alcançar os estágios terminais. Portanto, 
existem dois tipos de insuficiência renal: a aguda e a crônica, ambas com características específicas $^{4}$.

A Insuficiência Renal Aguda (IRA) tem como característica a redução abrupta da função renal, que se mantém por períodos variáveis, resultando na impossibilidade dos rins em exercer suas funções básicas de excreção e manutenção da homeostasia hidroeletrolítica do organismo ${ }^{5}$.

As alterações laboratoriais na IRA incluem a uremia progressiva, acidose, hipercalemia e hiponatremia. Geralmente há um aumento diário da creatinina sérica e do nitrogênio ureico. A acidose é moderada, mas quando o catabolismo está acelerado a sua progressão é mais rápida, do mesmo modo são mais rápidas as elevações da uréia e da creatinina ${ }^{6}$.

A Doença Renal Crônica (DRC) é uma síndrome metabólica caracterizada por uma situação clínica na qual os rins perdem progressivamente suas funções exócrinas de filtração, reabsorção e secreção de substâncias na urina, como também suas funções endócrinas ${ }^{7,8}$.

Os indivíduos com DRC têm comprometimento irreversível do tecido renal e das funções renais, retendo água, causando hipercalemia, apresentando hiponatremia e elevação progressiva dos catabólitos nitrogenados, uréia e creatinina?.

Na DRC, bem como na IRA, os rins reduzem a capacidade de excreção do potássio, o que leva o organismo, na tentativa de manter a homeostasia interna, disponibilizar mecanismos para tentar prevenir o acúmulo excessivo desse mineral no sangue, assim observam-se mecanismos adaptativos para aumentar a excreção de potássio nos néfrons remanescentes como também no intestino. Para que isso ocorra, os rins tornam-se mais eficientes na eliminação do potássio, aumentando a excreção desse mineral por meio das fezes ${ }^{10,11}$.

No tratamento de pacientes em diálise, a adequada homeostase do potássio representa um problema frequente. Tanto a hipocalemia - con- centração do potássio no soro inferior a 3,5mEq/ I - quanto a hipercalemia - concentração plasmática acima de 5,0mEq/l - sabidamente afetam a excitabilidade da célula do músculo cardíaco, propiciando o desenvolvimento de arritmias e morte súbita1,12.

A restrição dietética deve ser mais rigorosa para pacientes em Hemodiálise (HD), sobretudo para os anúricos. Apesar de a alimentação contribuir de forma significativa com os níveis séricos de potássio, outras condições também podem causar ou agravar a hipercalemia e devem ser tratadas sempre que possível ${ }^{13}$.

De acordo com Dinalli \& Portero ${ }^{8}$, o potássio da dieta só deve ser restrito se o nível plasmático desse mineral estiver acima do normal. Geralmente, isso só é necessário em pacientes que evoluem para acidose metabólica, com constipação intestinal e em uso de drogas como os inibidores da enzima conversora de angiotensina.

Contudo, Louis \& Dolan ${ }^{14}$ alertam sobre a restrição do potássio da dieta, que exige uma instrução cuidadosa do paciente renal sobre as fontes e as quantidades de alimento a serem diminuídas ou evitadas, além dos riscos e consequências da hipercalemia.

Pacientes com a doença avançada estão em risco de terem a ingestão dietética inadequada, uma vez que as dietas prescritas são comumente baixas em alguns nutrientes e altas em outros, sendo comum a desnutrição. A adequação da dieta e o estado nutricional do paciente devem ser monitorados periodicamente ${ }^{15}$.

Em geral, recomenda-se que a ingestão de potássio seja inferior a 70mEq/dia ( 3g/dia). Hortaliças, frutas, leguminosas e oleaginosas apresentam elevado teor de potássio e o processo de cozimento em água de hortaliças e frutas promove perda significativa desse eletrólito, com valores em torno de $60 \%{ }^{13}$.

Para que os vegetais com elevado teor desse mineral não sejam excluídos da dieta, alguns métodos têm sido estudados para minimizar essa concentração, como a ebulição em grande quanti- 
834 | C. cOPETTI et al.

dade de água - descartada após a cocção -, que compreende trocas químicas, físico-químicas e estruturais dos componentes dos alimentos provocadas intencionalmente por efeito do calor ${ }^{8,14,16,17}$.

Na cocção, o aquecimento é resultado do aporte de energia ao sistema, decorrente da transferência de calor. Nos diferentes métodos de cozimento, as formas de transferência de calor, a temperatura, a duração do processo, e o meio de cocção são alguns dos fatores responsáveis pelas alterações químicas e físicas que podem modificar o valor nutricional dos alimentos ${ }^{18,19}$.

Sendo assim, o objetivo deste estudo foi avaliar a concentração de potássio em vegetais crus e cozidos sob diferentes formas de cocção, além de verificar se o remolho e as técnicas de cocção têm eficácia na redução da concentração desse mineral.

\section{M É T O D O S}

Este estudo foi do tipo experimental com delineamento inteiramente casualizado, esquema fatorial $3 \times 5$ (três vegetais $X$ cinco métodos de pré-preparo e preparo) e três repetições nas análises.

Como critério de seleção dos alimentos, usou-se a diversidade dos pigmentos e selecionaram-se, entre esses, os mais populares e com elevado teor de potássio: batata, brócolis e cenoura. Para a seleção dos vegetais, verificaram-se os valores de potássio dos alimentos na Tabela Brasileira de Composição de Alimentos (TACO ${ }^{20}$, apenas como referência.

\section{Pré-preparo e preparo das amostras}

Foram cedidos por um estabelecimento comercial da cidade de Santa Maria (RS) três quilos de batata, brócolis e cenoura, que foram colhidos na mesma época e oriundos do mesmo lote para a realização deste estudo. O pré-preparo e preparo das amostras foram realizados no Laboratório de Técnica Dietética do Centro Universitário Franciscano (UNIFRA).
A batata e a cenoura foram homogeneizadas, selecionadas, lavadas em água corrente e, depois de retirada a epiderme, foram cortadas em rodelas de $2 \mathrm{~cm}$ de espessura. As inflorescências dos brócolis foram selecionadas, lavadas em água corrente, tendo sido retirados as folhas e os talos. As hortaliças foram distribuídas em cinco métodos de pré-preparo e preparo e divididas em amostras de $100 \mathrm{~g}$ cada uma para $200 \mathrm{~mL}$ de água. Foi padronizado para todos os métodos de preparo o uso de quantidade de água suficiente para cobrir os vegetais. Algumas avaliações preliminares foram realizadas para que fosse estabelecido o correto tempo de cocção para cada tipo de hortaliça e método de preparo, visando que ficassem "al dente".

A água utilizada foi do tipo deionizada para que não houvesse interferência nos valores de micronutrientes.

Esses vegetais foram avaliados in natura, sem uso de método de remolho ou cocção, e considerados o controle do experimento.

\section{Remolho}

No método de remolho, para cada amostra $(100 \mathrm{~g})$ de vegetal in natura foram adicionados $200 \mathrm{~mL}$ de água deionizada, à temperatura ambiente de $20^{\circ} \mathrm{C}$ e estabelecido o tempo de quatro horas, desprezando-se uma vez a água utilizada.

\section{Preparo em ebulição}

Foram cozidos uma única vez $100 \mathrm{~g}$ de cada vegetal in natura em 200mL de água deionizada, por ebulição em fogão convencional sob temperatura de $98^{\circ} \mathrm{C}$, verificada com termômetro digital do tipo espeto e da marca Instruterme ${ }^{\circledR}$, tendo sido, posteriormente, a água desprezada. Para a cocção da batata, brócolis e cenoura, usaram-se os tempos de $13 \mathrm{~min}, 10 \mathrm{~min}$ e $17 \mathrm{~min}$, respectivamente. 


\section{Preparo em forno de micro-ondas}

Foram cozidos uma única vez $100 \mathrm{~g}$ de cada vegetal in natura em $200 \mathrm{~mL}$ de água deionizada, em forno de micro-ondas da marca Sanyo modelo EM-604T com frequência de onda de 2450MHz sob potência máxima (100MHz), tendo sido, posteriormente, a água desprezada. Para a cocção das batata, dos brócolis e da cenoura, utilizaram-se os tempos de $7 \mathrm{~min}, 5 \mathrm{~min}$ e $9 \mathrm{~min}$, respectivamente.

\section{Preparo em panela de pressão}

Foram cozidos uma única vez $100 \mathrm{~g}$ de cada vegetal in natura em $200 \mathrm{~mL}$ de água deionizada, em panela de pressão com fluxo contínuo de pressão de 1 ATM à temperatura de $116^{\circ} \mathrm{C}$, tendo sido, posteriormente, a água desprezada. Para a batata, os brócolis e a cenoura, usaram-se os tempos de $10 \mathrm{~min}, 8 \mathrm{~min}$ e $10 \mathrm{~min}$, respectivamente.

\section{Determinação de potássio (K)}

As amostras in natura e remolho foram picadas; as amostras coccionadas foram amassadas com garfo para facilitar o processo de moagem, acondicionadas em papel alumínio, embaladas em saco plástico, etiquetadas e analisadas na Universidade Federal de Santa Maria (UFSM) pelo Centro de Ciências Rurais (CCR) no Laboratório de Ecologia Florestal (LABEFLO).

A preparação das amostras foi realizada por meio de secagem em estufa com circulação forçada de ar quente a $65-70^{\circ} \mathrm{C}$, sem a lavagem do material. A dupla moagem foi feita através da trituração do material seco em moinhos de facas de aço inox até passar em malha de 2-3mm; em seguida, esse material foi homogeneizado em moinho tipo Wilie, obtendo-se uma amostra final de 10-15g para as análises.

O teor de potássio no tecido vegetal varia na maior parte dos casos entre 0,2 e 10\%. As hortaliças sofreram digestão líquida com ácido sulfúrico e peróxido de hidrogênio, seguindo a metodologia descrita por Duncan ${ }^{21}$, e as amostras foram avaliadas por fotometria de chama IL mod. 443, ajustando-se a sensibilidade do aparelho com os padrões adequados.

Os dados obtidos foram analisados por meio de Análise de Variância (ANOVA) e teste de Tukey para a comparação das médias entre as amostras, utilizando-se um nível de significância de $5 \%$. Para a análise dos dados foi utilizado o programa ESTAT versão 2.0.

\section{RESULTADOS E DISCUSSÃO}

Os resultados foram expressos em $\mathrm{mg} / 100 \mathrm{~g}$ de alimento; o teor de potássio na batata crua foi de $293,7 \mathrm{mg} / \mathrm{g}$ e na batata que ficou em remolho foi de $232,2 \mathrm{mg} / \mathrm{g}$, verificando-se que não houve diferença estatística significativa na redução do mineral potássio (Tabela 1).

Entretanto, os métodos de ebulição, micro-ondas e pressão reduziram os teores de potássio a $197,3 \mathrm{mg} / \mathrm{g}, 170,3 \mathrm{mg} / \mathrm{g}$ e $187,2 \mathrm{mg} / \mathrm{g}$, respectivamente; quando comparados ao vegetal cru, mostraram-se reduções estatisticamente significativas. Todavia, esses três métodos de cocção quando comparados ao remolho não apresentaram diferença estatística significativa.

Os brócolis (Tabela 1), quando submetidos a diferentes métodos de cocção, apresentaram perdas diferenciadas nos valores de potássio. Estatisticamente foi verificado uma diferença signi-

Tabela 1. Teores de potássio em hortaliças cruas e submetidas a diferentes processamentos, em estudo realizado em Santa Maria (RS), 2007

\begin{tabular}{lccc}
\hline Tratamentos & Batata $(\mathrm{mg} / \mathrm{g})^{*}$ & ${\text { Brócolis }(\mathrm{mg} / \mathrm{g})^{*}}^{*}$ & ${\text { Cenoura }(\mathrm{mg} / \mathrm{g})^{*}}^{*}$ \\
\hline Cru & $293,7^{\mathbf{a}}$ & $410,7^{\mathbf{a}}$ & $388,4^{\mathbf{a}}$ \\
Remolho & $232,2^{\text {ab }}$ & $347,4^{\text {ab }}$ & $315,0^{\text {ab }}$ \\
Ebulição & $197,3^{\mathbf{b}}$ & $308,1^{\text {ab }}$ & $309,9^{\text {ab }}$ \\
Micro-ondas & $170,3^{\mathbf{b}}$ & $280,1^{\text {bc }}$ & $243,3^{\mathbf{b}}$ \\
Pressão & $187,2^{\mathbf{b}}$ & $167,3^{\mathbf{c}}$ & $210,6^{\mathbf{b}}$ \\
\hline
\end{tabular}

As médias seguidas da mesma letra não diferem significativamente entre si pelo teste de Tukey $(p=0,05)$.

"níveis de potássio em mg/g. 
ficativa entre o brócolis cru quando comparado ao método de pressão (167,3mg/g) e micro-ondas $(280,1 \mathrm{mg} / \mathrm{g})$. Ao mesmo tempo em que cru, remolho e ebulição não diferiram significativamente entre si, e o método em micro-ondas e pressão não obtiveram diferença estatística relevante.

Santos et al. ${ }^{22}$ realizaram um estudo sobre diferentes tempos de cozimento e suas influências nos teores de potássio em folhas de brócolis e constataram que esse mineral teve seus teores diminuídos com o aumento do tempo de cozimento, mostrando ter sido removido pela água. As folhas dos brócolis obtiveram o menor teor de potássio - 1560mg/g -, apresentando perda de 27,1\% do seu conteúdo após aplicação dos tratamentos.

Os resultados para a cenoura mostram que essa hortaliça apresentou o mesmo perfil que a batata; portanto, pode-se verificar que o teor de potássio na cenoura crua $(388,4 \mathrm{mg} / \mathrm{g})$, sob remolho $(315,0 \mathrm{mg} / \mathrm{g})$ e em ebulição $(309,9 \mathrm{mg} / \mathrm{g})$ não diferiram estatisticamente entre si, igualmente para os métodos micro-ondas (243,3mg/g) e pressão $(210,6 \mathrm{mg} / \mathrm{g})$. Todavia, os métodos micro-ondas e pressão obtiveram diferença estatística em relação ao vegetal cru.

Para que os vegetais com hipercalemia não sejam excluídos da dieta, alguns métodos têm sido estudados para minimizar a concentração de potássio. O conteúdo desse mineral presente nesses alimentos pode ser reduzido por meio de ebulição em grande quantidade de água, que deve ser descartada após a cocção8 8,14,16.

De acordo com Riella \& Martins ${ }^{10}$, é possível também reduzir a quantidade de potássio dos vegetais usando técnicas de pré-preparo e preparo de alimentos como descascar, picar, hidratar por algumas horas e, depois, cozinhar em bastante água. O método exige que toda a água usada seja desprezada para que uma quantidade substancial - aproximadamente $60 \%$ - do potássio seja descartada.

Em seu estudo, Tsaltas ${ }^{16}$, preocupado em fornecer fontes de vegetais sem prejudicar a dieta de pacientes com insuficiência renal crônica, trabalhou com processos de cozimento em vegetais de modo que a maioria do potássio fosse removida. Nesse estudo, o autor comparou os alimentos frescos aos coccionados uma vez; e em outro procedimento aliou o remolho à cocção, verificando que esse foi o processo de maior remoção de potássio nos vegetais.

Cuppari et al.23, afirma que no meio hospitalar adota-se a cocção por duas vezes, desprezando-se a água a cada vez; dessa forma, a autora e colaboradores realizaram um estudo coccionando os vegetais uma única vez e também duas vezes e verificaram que apenas uma cocção é suficiente para retirada de potássio dos vegetais. Sugeriu-se assim uma única cocção do alimento em grande quantidade de água, que deve ser desprezada posteriormente. Dessa forma, mantêm-se a aparência e a consistência firme do alimento, minimizando o problema da baixa aceitabilidade pelo paciente.

Santos, et al. ${ }^{22}$ avaliaram a redução de potássio em folhas de diferentes vegetais; para cada $100 \mathrm{~g}$ de alimento eles utilizaram $1000 \mathrm{~mL}$ de água. Entretanto, neste presente estudo, foram utilizados apenas $200 \mathrm{~mL}$ de água para cada $100 \mathrm{~g}$ de vegetal: o suficiente para cobrir o alimento. Pode-se concluir que a quantidade de água não interfere nos valores de redução do mineral, evitando assim a perda de outros micronutrientes importantes na dietoterapia renal.

No presente estudo observou-se que além da cocção por ebulição, existe a opção de coccionar os vegetais nos métodos micro-ondas e pressão, que também proporcionam redução nos teores de potássio.

De acordo com Silva et al. ${ }^{24}$, a cocção em forno de micro-ondas permite alcançar temperaturas superiores à do forno convencional, o que, teoricamente, resultaria em perda mais expressiva de micronutrientes por degradação térmica. No entanto, essa redução pode ser minimizada pelo fato de a cocção em micro-ondas permitir um 
aquecimento mais uniforme e mais rápido do alimento, quando comparado ao cozimento convencional em que a condução de calor se processa de maneira mais lenta.

É necessário controlar a cocção de cada vegetal especificamente ou orientar-se por tabelas pré-estabelecidas de tempo de cocção para não ultrapassar o ponto de cocção suficiente ${ }^{25}$.

\section{O N CLUS Ã O}

Nas condições deste experimento, pode-se concluir que:

- O processamento por remolho não obteve resultados satisfatórios, pois não teve redução significativa se comparado aos alimentos crus.

- Os três métodos de cocção - ebulição, micro-ondas e pressão - foram eficazes na redução dos teores de potássio nas hortaliças, comprovando a instabilidade do mineral perante a água e o processamento térmico.

- Das hortaliças avaliadas, os brócolis foram os mais sensíveis a perdas de potássio.

- Para a batata e a cenoura, os métodos de cocção foram todos eficazes; para os brócolis, a cocção sob pressão foi mais expressiva.

Sugere-se que sejam realizados novos estudos com condições experimentais similares e diferentes, pois existe escassez de material científico atualizado. Além disso, vários fatores podem influenciar os diferentes tipos de cocção, como tempo, temperatura, recipiente, potência e frequência das ondas eletromagnéticas de micro-ondas. Este estudo é de grande relevância para pacientes renais e profissionais que indicam em seus consultórios métodos de pré-preparo e preparo que precisam ser mais investigados.

\section{A GRADE CIMENTO}

Ao Supermercado Dois Irmãos de Santa Maria/RS pelo fornecimento das hortaliças.

\section{COLABORADORES}

C. COPETTI participou da execução de todo o trabalho, principalmente da coleta dos dados, da execução dos experimentos, da análise e da interpretação dos dados, da redação e correções do artigo. V.R. OLIVEIRA orientadora do projeto e do artigo auxiliou na coleta de dados; na análise e na interpretação dos dados e redação e nas correções do artigo. P. KIRINUS auxiliou na coleta de dados e na execução dos experimentos laboratoriais.

\section{REFERÊ N CIAS}

1. Vieira Neto OM, Moysés Neto M. Distúrbios do equilíbrio hidroeletrolítico. Anais da $36^{\circ}$ Simpósio de urgências e emergências nefrológicas. Ribeirão Preto; 2003

2. Osorio FV, Linas SL. Disorders of potassium metabolism. In: Schrier RW, editor. Atlas of diseases of the kidney. 2003. Available from: <http://www. kidneyatlas.org>.

3. Krenitsky J. Nutrition in renal failure: myths and management. Pract Gastroenterol (USA). 2004; 23(9):40-59.

4. Thadhani R, Pascual M, Bonventre JV. Acute renal failure. N Engl J Med. 1996; 334:1448.

5. Garcia TPR, Romero MP, Poletti NAA, Cesarino CB, Ribeiro RCHM. Principais motivos de internação do paciente com insuficiência renal aguda na unidade de terapia intensiva. Arq Ciênc Saúde. 2005; 12(3): 146-50.

6. D'avila DO, Traezel M, Glock L, Insuficiência renal aguda tratada por diálise em unidade de tratamento intensivo (análise de 124 pacientes consecutivos). J Bras Nefrol. 1997; 19(1):21-31.

7. Cabral PC, Diniz AS, Arruda IKG. Avaliação nutricional de pacientes em hemodiálise. Rev Nutr. 2005; 18(1):29-40. doi: 10.1590/S1415-52732005 0010003.

8. Dinalli SC, Portero KCC. Terapia nutricional em pacientes com insuficiência renal crônica. Nutr Pauta. 2005; 13(74):30-3.

9. Papini H, Santana R, Ajzen H, Ramos OL, Pestana JOM. Alterações metabólicas e nutricionais e orientação dietética para pacientes submetidos a transplante renal. J Bras Nefrol. 1996; 18(4):356-69.

10. Riella MC, Martins C. Nutrição e o rim. Rio de Janeiro: Guanabara Koogan; 2001. Cap.12, p.24-5. 
11. Helou CMB. Potássio e bicarbonato. J Bras Nefrol. 2004; 26(3 Supl. 1):22-5.

12. Redaelli $B$, Locatelli F, Limido $D$, Andrulli S, Signorini MG, Sforzini S, et al. Effect of a new model of hemodialysis potassium removal on the control of ventricular arrhythmias. Kidney Int. 1996; 50:609-17.

13. Cuppari L. Guias de medicina ambulatorial e hospitalar: nutrição clínica no adulto. $2^{a}$ ed. São Paulo: Manole; 2005. p.189-220.

14. Louis CJ, Dolan EM. Removal of potassium in potatoes by leaching. J Am Diet Assoc. 1970; 57:42-3.

15. Heaney RP. Biologia óssea na saúde e na doença: guia didático. In: Shils M, Olson JA, Shike M, Ross AC. Tratado de nutrição moderna na saúde e na doença. 9a ed. Barueri: Manole; 2003.

16. Tsaltas, T. Extraction of potassium from foods for uremic patients. Am J Clin Nutr. 1969; 22(4):490-3.

17. Philippl ST. Nutrição e técnica dietética. Barueri: Manole; 2003.

18. García-Arias MT, Pontes EA, García-Linares MC. Cooking-freezing-reheating (CFR) of sardine (Sardina pilchardus) fillets: effect of different cooking and reheating procedures on the proximate and fatty acid compositions. Food Chem (Great Britain). 2003; 83(3)349-56.

19. Potter NN, Hotchkiss JH. Ciência dos alimentos. $5^{a}$ ed. Zaragoza: Acribia; 1995. p.667.
20. Universidade Estadual de Campinas. Tabela Brasileira de Composição de Alimentos. Versão 2. Campinas; NEPA; 2006.

21. Duncan, L. Clinical analysis by atomic absorption spectroscopy. Springvale: Varian Spectron Pty; 1976. p.55.

22. Santos MAT, Abreu CMP, Carvalho VD. Efeito de diferentes tempos de cozimento nos teores de minerais em folhas de brócolis, couve-flor e couve (Brassica oleracea L.) Ciênc Agrotec. 2003; 27(3): 597-604.

23. Cuppari L, Amancio OMS, Nóbrega M, Sabbaga E. Preparo de vegetais para utilização em dieta restrita em potássio. Nutrire: Rev Soc Bras Alim Nutr. 2004; (28):1-7.

24. Silva PT, Lopes MLM, Valente-Mesquita VL. Efeito de diferentes processamentos sobre o teor de ácido ascórbico em suco de laranja utilizado na elaboração de bolo, pudim e geléia. Cienc Tecnol Aliment. 2006; 26(3):678-82.

25. Ornellas LH. Técnica dietética: seleção e preparo de alimentos. $7^{a}$ ed. São Paulo: Atheneu; 2001. cap.8, p.194 e 203-4.

Recebido em: 13/8/2008

Versão final reapresentada em: 17/8/2009 Aprovado em: 4/5/2010 